\title{
Finite Element Simulation Analysis of Compressed Material in Intelligent Compaction
}

\author{
Changmin Yang', Ruining Wei ${ }^{1}$, Yanfang Yao², Quanle Wang1 \\ ${ }^{1}$ College of Civil Engineering Hebei University, Baoding, China; \\ ${ }^{2}$ Hebei College of Science and Technology, Baoding, China \\ Email: changmyang@126.com
}

How to cite this paper: Yang, C.M., Wei, R.N., Yao, Y.F. and Wang, Q.L. (2018) Finite Element Simulation Analysis of Compressed Material in Intelligent Compaction. Engineering, 10, 173-186. https://doi.org/10.4236/eng.2018.104012

Received: January 30, 2018

Accepted: April 25, 2018

Published: April 28, 2018

Copyright ( 92018 by authors and Scientific Research Publishing Inc. This work is licensed under the Creative Commons Attribution International License (CC BY 4.0).

http://creativecommons.org/licenses/by/4.0/

(c) (i) Open Access

\begin{abstract}
In order to improve the quality of the project, we adopt the intelligent compaction control system and collect CMV values through experiments. In the experiment using finite element simulation software to simulate and analyze. From the simulation results to analyze the road surface displacement and stress trends, derived from the displacement of the pressed material in the fifth pass, the sixth pass is almost the same, the rate of change close to 0 , can be considered pressed material has the desired pressure. The actual degree is in good agreement with the actual compaction of sand filling, indicating that the compaction state of the pressed material can also be verified from the stress angle of the pressed material. The stress change from the weak vibration to the strong vibration load increases first and then decreases rapidly, and the reduction of strong vibration is more obvious. Therefore, the simulation result also shows that the strong vibration has the better compaction effect than the weak vibration.
\end{abstract}

\section{Keywords}

Intelligent Compaction CMV Values Finite Element Compactness Variation Trend

\section{Introduction}

In the process of engineering construction, the compaction effect is directly related to the quality, safety performance and durability of the project, and is closely related to the safety of people's life and property [1]. Therefore, the compaction of the subgrade is an important link in the highway construction engineering, and its compaction is also the main influence factor of the pavement damage [2]. If the bearing capacity of the roadbed is less than the require- 
ment and the stability is poor, it will cause the road collapse, longitudinal crack and even structural damage in a short time [3]. In fact, the extra cost of repairing the roadbed is also considerable; meanwhile, the repair process will inevitably affect the traffic, thus affecting people's normal travel life.

However, the emergence of intelligent compaction technology solves this practical problem well. Intelligent compaction [4], the image that is the operator of the roller with real-time feedback can visually observe the degree of compaction of the rolling area. Of course, to achieve this goal, roller, roadbed, induction equipment, display equipment, the overall composition of the establishment of real-time response mechanism to accurately guide the construction [5]. The emergence of smart compaction technology is inevitable and promising, both in terms of compaction effects and overall economic cost planning. At present, China applies the technology relatively extensively in terms of railway construction and has formulated corresponding normative standards [6]. In the aspect of intelligent compaction of highway subgrade, it is still not very mature, and it is still in the stage of theoretical experiment.

In the theoretical experimental stage of subgrade, the CMV index controlled by intelligent compaction system reflects the change of resistance of the soil to the vibration wheel and indirectly reflects the degree of soil compaction. With the aid of finite element simulation analysis software [7], starting from the pressed material, the theory by simulating rolling process, the stress and displacement of pressed material can be analyzed to investigate whether the stress and displacement curves can reflect the compactness of the pressed material and how it is reflected [8].

\section{Finite Element Simulation Analysis}

\subsection{Purpose}

The use of COMSOL Mulyiphysics software simulation analysis, through the analysis found that the compaction of the pressed material can be achieved through the intelligent compaction system indirectly collected resistance values and pressure material stress and displacement changes are reflected in both [9]. And under the action of the vibratory roller, the variation law of the stress and displacement of the pressed material can be found out. At the same time, some valuable references are provided for the practicability of the intelligent compaction system [10].

\subsection{Theoretical Model}

\subsubsection{Geometric Model}

This experiment uses COMSOL Mulyiphysics software to analyze the compaction process used. And the compaction process is static pressure once, weak vibration one time, strong vibration four times, the model is a two-dimensional silty soil layer, a length of 50 meters, a thickness of $30 \mathrm{~cm}$. Model shown in Figure 1. 


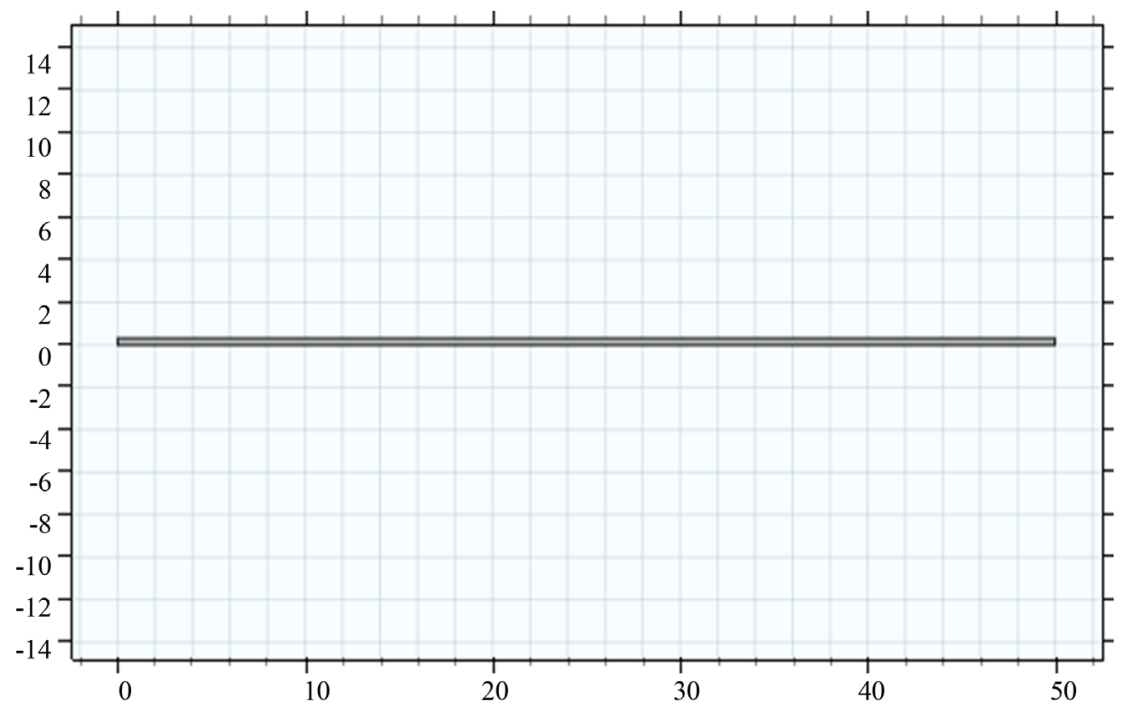

Figure 1. Geometric model.

\subsubsection{Grid Model}

The grid adopts the mapping method, and the total number of units is 22,992, and the local enlargement is shown in Figure 2.

\subsection{Simulation Results and Analysis}

The test road project is located in the Baoding area of the North China Plain, the area belongs to the key grain-producing area, along the flat terrain, there is no protruding hills and ridge, can be used as a borrow site. The soil quality along the project is mostly silt and some silty clay. The shaping index is about 10 and can be used as roadbed filler after drying. The maximum particle size of the filler should be less than $150 \mathrm{~mm}$. In order to bring the original layer of soil on the influence factors of CMV value, to achieve the ideal test, decided to choose after the roadbed filling height to $2 \mathrm{~m}$, subgrade compaction to using intelligent system for static pressure 1 time, weak vibration 1 times, strong vibration 4 times.

\subsubsection{Pavement Average Displacements and Average Stress Curves with Different Compaction Times}

The software actually considers the elasto-plastic constitutive model of soil. Due to the fact that the external load of the actual simulation is small and the concentrated load simplified by the compactor is only obvious to the local, the soil actually only undergoes the elastic deformation process and has not yet reached the plastic deformation stage.

Figure 3 shows that the first pass static pressure, the average soil surface displacement of about $2.25 \mathrm{e}-7 \mathrm{~m}$, the average stress of about $0.8 \mathrm{~Pa}$. The second time the weak vibration, the average displacement and stress are reduced. When the third pass for strong vibration, the displacement and stress have picked up. With the increase of the number of compaction, the displacement and stress show a trend of rapid decrease. Finally, when the sixth compaction is carried out, the displacement and stress of soil tend to be gentle. With the fifth and sixth pass the 


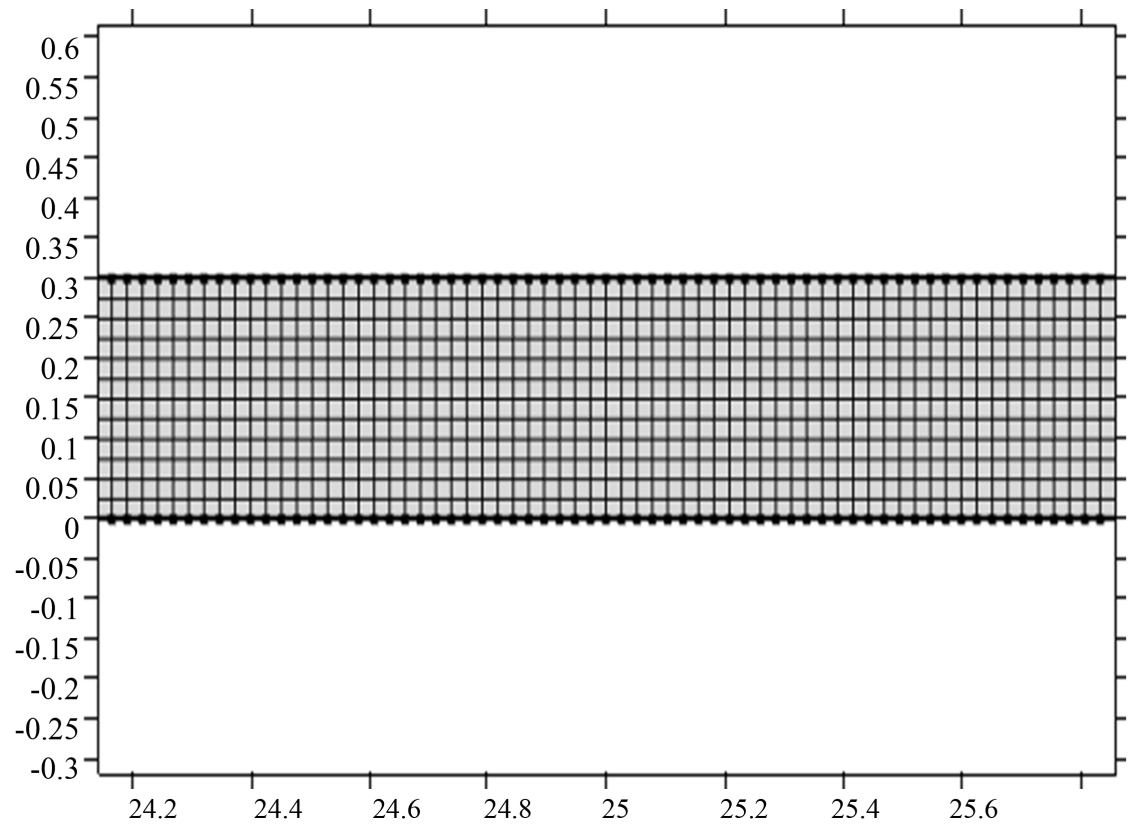

Figure 2. Grid model.

average displacement rate of change to specify, the software to extract the fifth pass and the sixth pass the average displacement of $2.51 \mathrm{e}-8 \mathrm{~m}, 2.505 \mathrm{e}^{-}-8 \mathrm{~m}$, the average rate of change of displacement is $\frac{(2.51-2.505) e^{-8}}{6-5}=5 \times 10^{-3} e^{-8} \approx 0$. In dicating that the material being pressed against the external load capacity to strengthen and continue to vibrate compaction no effect, we can think that the soil has reached a strong state of compaction. Therefore, it can be concluded from the comparison of the above figure that the effect of strong vibration is better than the effect of weak vibration.

\subsubsection{The Distribution of Road Displacement Distribution and Pavement Displacement Distribution Curve under Different Compaction at the End Time}

1) The first compaction of the end ( $t=62.5 \mathrm{~s})$

As shown in Figure 4 and Figure 5, when the time of $t=62.5 \mathrm{~s}$ is carried out, the roller is the final moment of the static pressure phase, where the load moves from the initial position to the right end. At this point, the displacement and stress of the pavement in most regions of relatively uniform, just near the road along the length of one-third and two-thirds of large displacement and large stress and the vertical downward displacement direction, road each location convex or drum warping phenomenon will not occur. The displacement and stress are still small in the vibration end position and the surrounding area. At this time, the maximum displacement is about 1.4 microns and the maximum stress is $200 \mathrm{~Pa}$.

2) The second compaction of the last $(t=125 \mathrm{~s})$

As shown in Figure 6 and Figure 7, when the time of $t=125 \mathrm{~s}$ is carried out, 


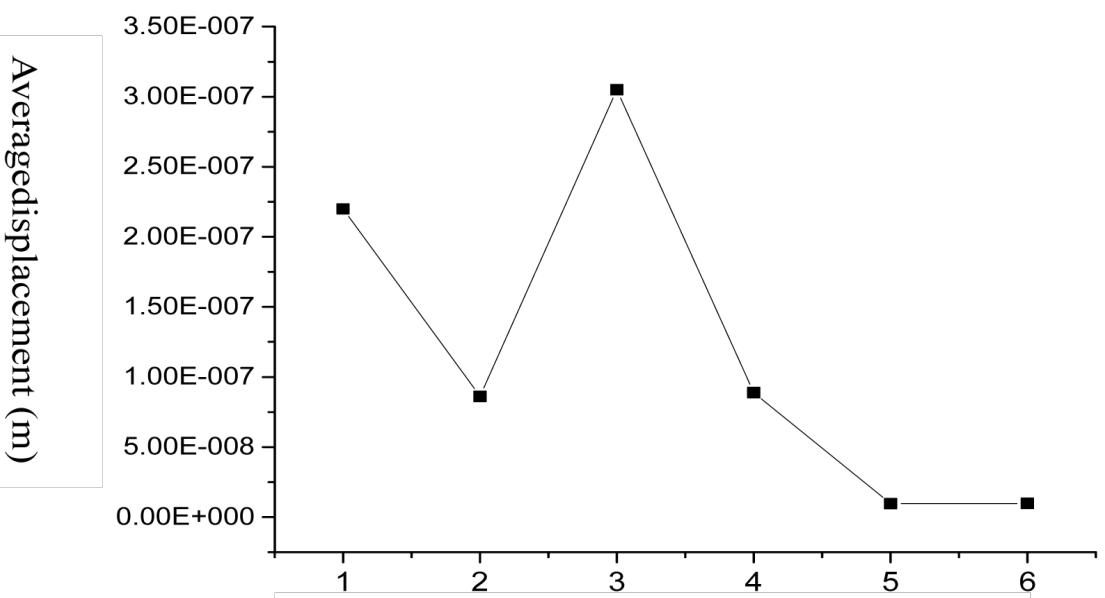

(a)

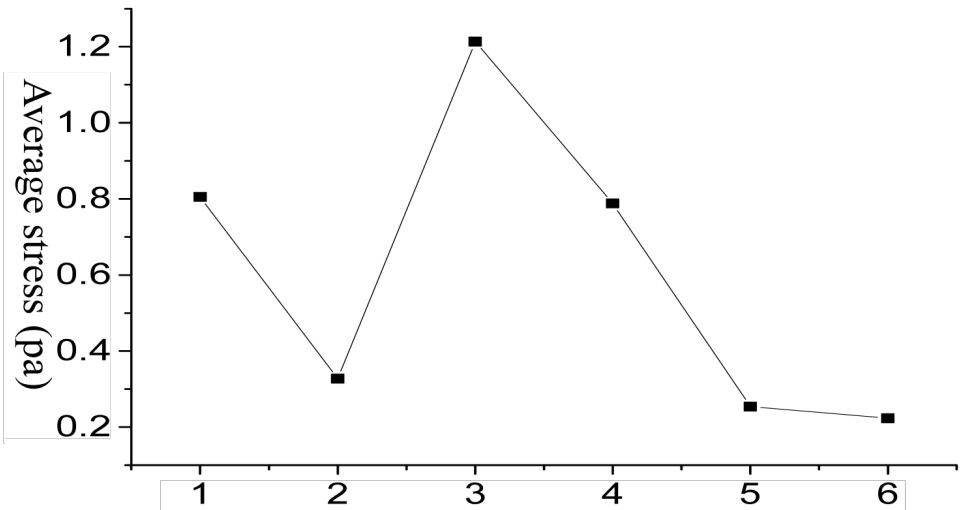

(b)

Figure 3. Pavement average displacements and average stress curves with different compaction times. (a) Compaction of the number; (b) Compaction of the number.

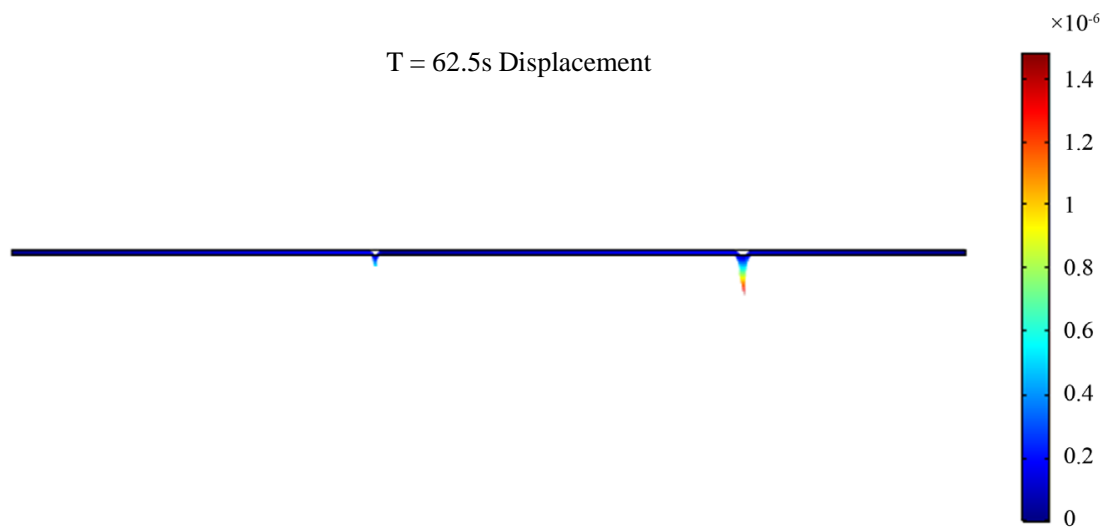

Figure 4. Displacement changes at the end of the first pass (Static pressure).

the roller is the last moment of the weak vibration stage, that is, the load moves from the end position of the static pressure to the left end. At this time, the displacement in most areas of the road is still relatively uniform, and the road surface stress is uneven. The displacement is only in the center of the road and near 


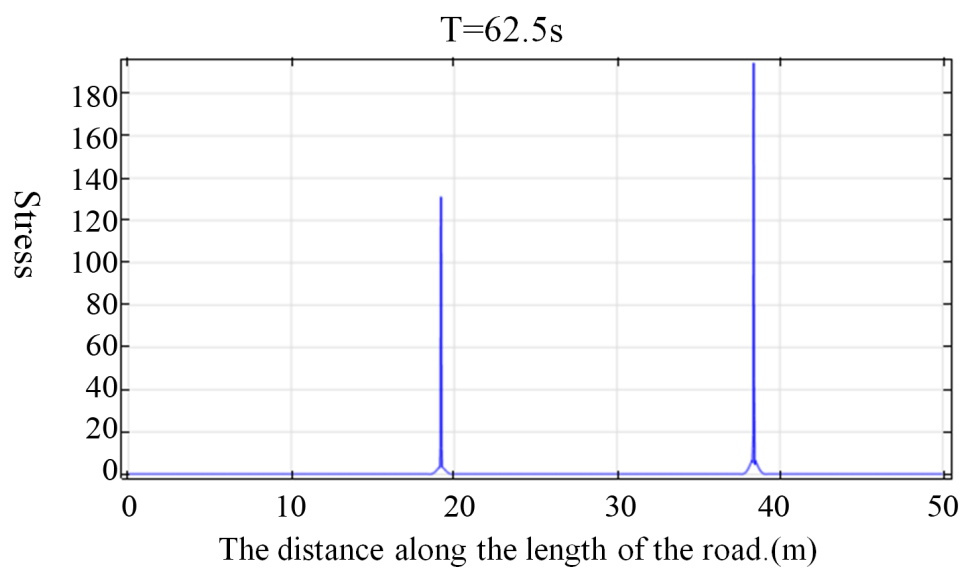

Figure 5. The stress changes at the end of the first compaction (Static pressure).

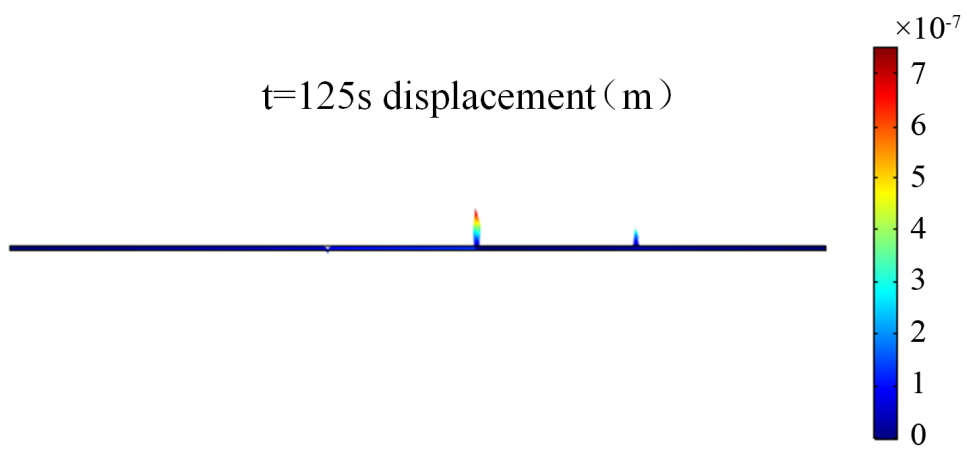

Figure 6. Displacement change at the end of second times compaction (Weak vibration).

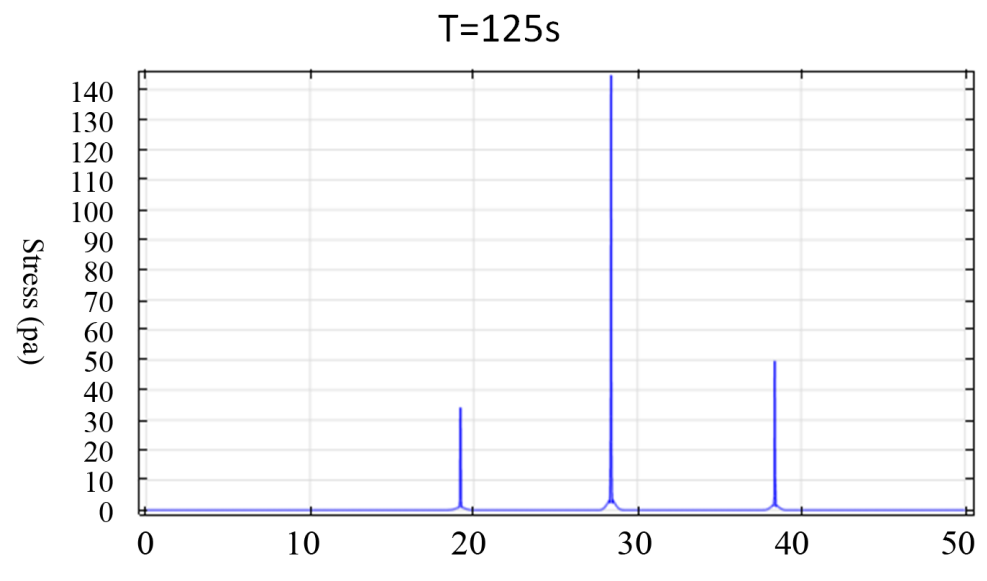

The distance along the length of the road.(m)

Figure 7. The stress is changed at the end of the second compaction (Weak vibration).

the right half of the area, and the displacement direction is vertical upward, and the road in this position will have a slight bulge or warping phenomenon. At this time, the maximum displacement value is 0.7 microns, while the maximum stress value is $140 \mathrm{~Pa}$. Compared with the static pressure phase, the maximum displacement and maximum stress of the road are reduced. The displacement 
and stress are still small in the vibration end of the roller and the surrounding area.

3) The third compaction of the last $(t=187.5 \mathrm{~s})$

As shown in Figure 8 and Figure 9, when the time $t=187.5 \mathrm{~s}$ is reached, the roller is the last moment of the first-pass strong vibration phase, that is, the load moves from the end position of the weak vibration to the rightmost end. At this moment, the displacements and stresses in most of the pavement are still relatively uniform, and only large displacements and stresses occur along the pavement along the center, with the direction of displacements going vertically downward. At this moment, the maximum displacement value is $0.5 \mu \mathrm{m}$ and the maximum stress value Is $100 \mathrm{~Pa}$, compared with the weak vibration phase, the maximum displacement and the maximum stress of pavement are reduced. However, the displacement and stress of the roller at the vibration end position and its vicinity are still small.

4) The fourth compaction of the last $(t=250 \mathrm{~s})$

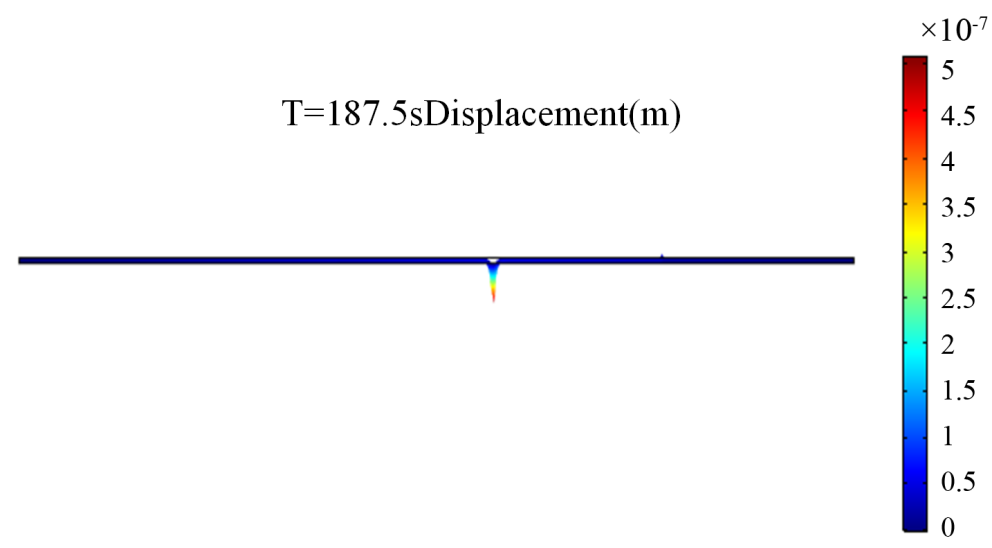

Figure 8. Displacement changes at the end of the third time compaction (Strong vibration).

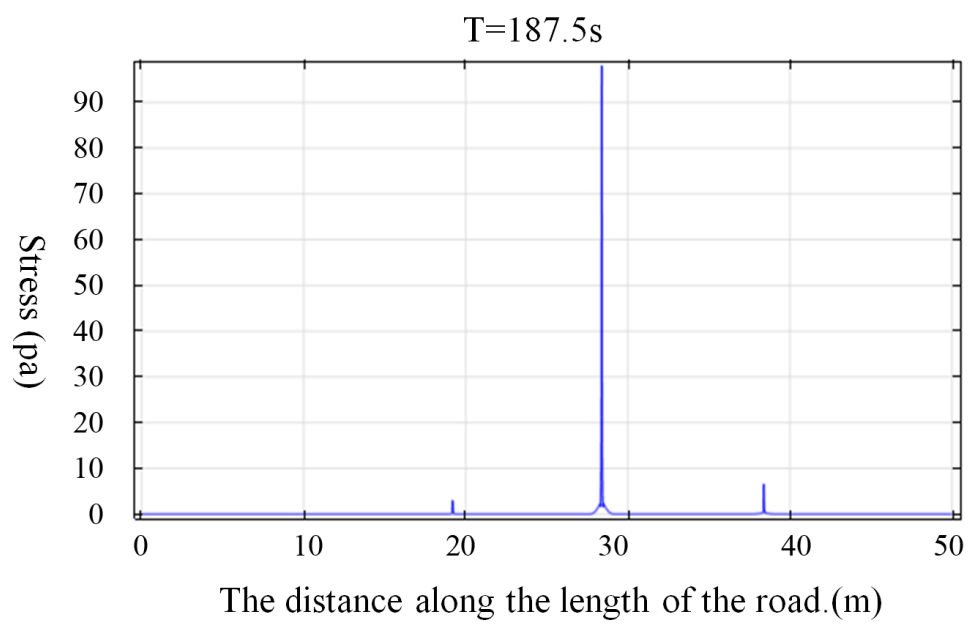

Figure 9. The stress changes at the end of the third compaction (Strong vibration). 
As shown in Figure 10 and Figure 11, when the moment to $t=250$ s, roller is the second time strong vibration phase at the moment, the load from the end of the first pass of strong vibration position moves to the left side, at this point, the road in most regions of the displacement and stress is relatively uniform, just near the road along the center of large displacement, vertical displacement direction, at this point, the maximal displacement value of 0.5 microns, the maximum stress value of $900 \mathrm{pa}$, compared with the first pass is strong vibration phase, the road of the maximal displacement is not too big change, but reduce the trend is gradually slow; The maximum stress on the road has rebounded. The displacement and stress are still small in the vibration end of the roller.

5) The fifth compaction of the last $(t=321.5 \mathrm{~s})$

As shown in Figure 12 and Figure 13, when the moment to $t=321.5$ s, roller is the third time of strong vibration phase at the moment, the load from the end of the second strong vibration position moves to the right side, at this point, the road in most regions of displacement and stress is relatively uniform, just near

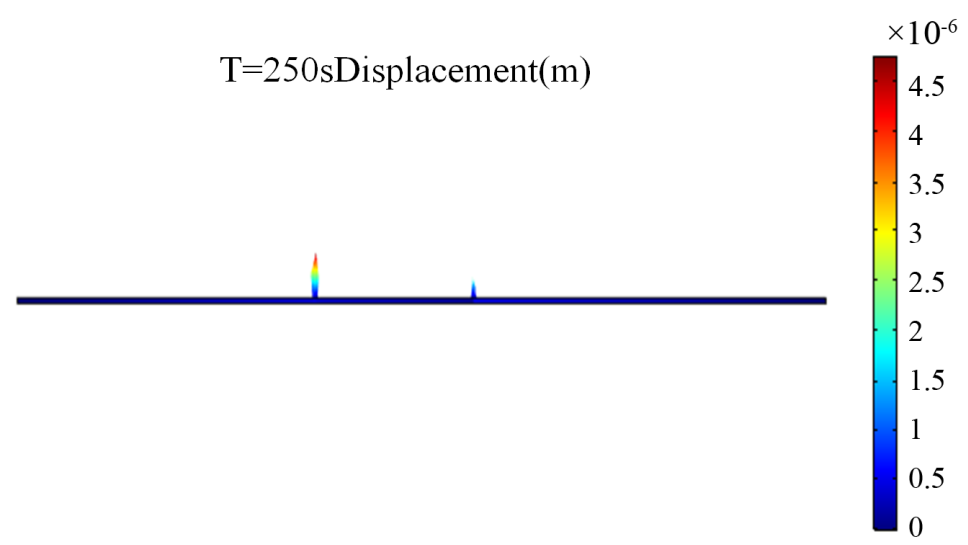

Figure 10. Displacement changes at the end of the fourth time compaction (Strong vibration).

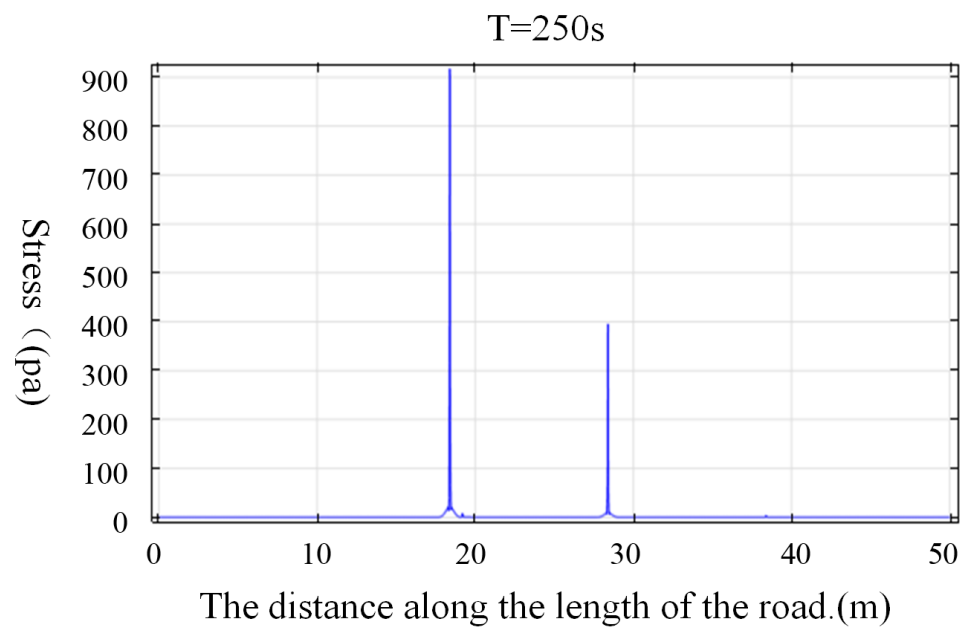

Figure 11. The stress changes at the end of the fourth compaction (Strong vibration). 


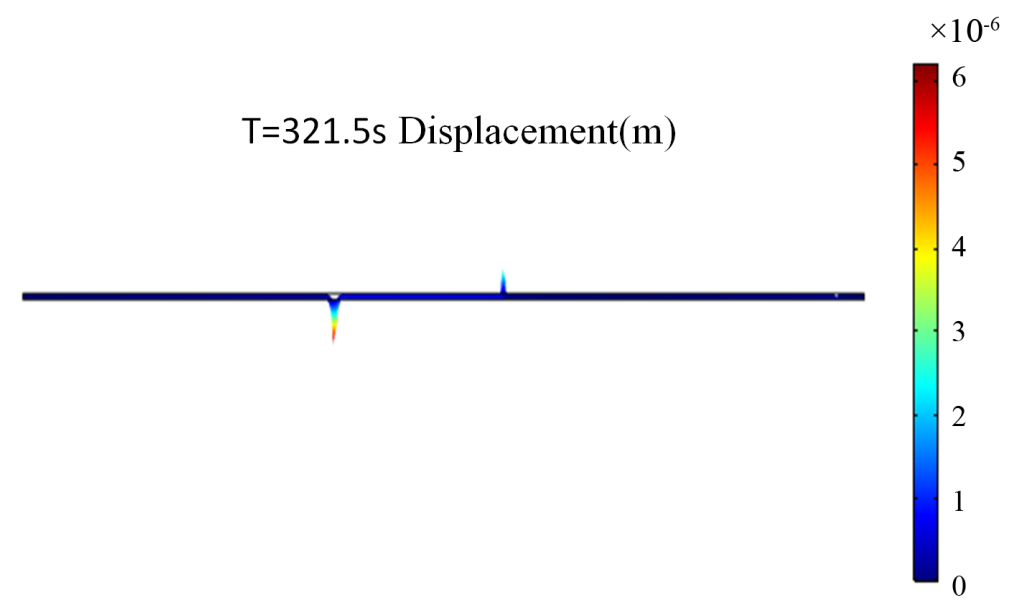

Figure 12. Displacement changes at the end of the fifth time compaction (Strong vibration).

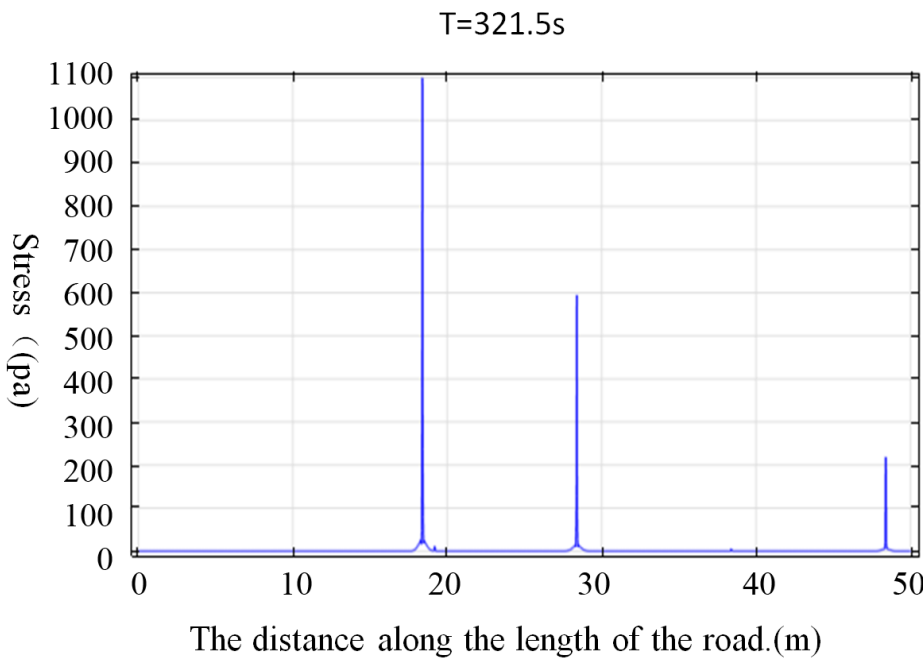

Figure 13. The stress changes at the end of the fifth compaction (Strong vibration).

the road along the center of large displacement, vertical displacement in a third position near the place down, near the center of vertical displacement direction, and at this point, the maximal displacement value of 0.5 microns, and the second time compared to the strong vibration phase, the road of the maximal displacement almost remain the same, and the maximum stress of 1100 pa. The displacement and stress are still small in the vibration end of the roller.

6) The sixth compaction of the last ( $t=375 \mathrm{~s})$

As shown in Figure 14 and Figure 15, when the moment to $t=375 \mathrm{~s}$, roller is the fourth times strong vibration phase at the moment, the load from the end of the third time the strong vibration position moves to the left side, at this point, the road in most regions of the displacement and stress is relatively uniform, just near the road along the center of large displacement and stress, at this point, the maximal displacement value of 0.16 microns, the maximum stress value of $35 \mathrm{pa}$, 


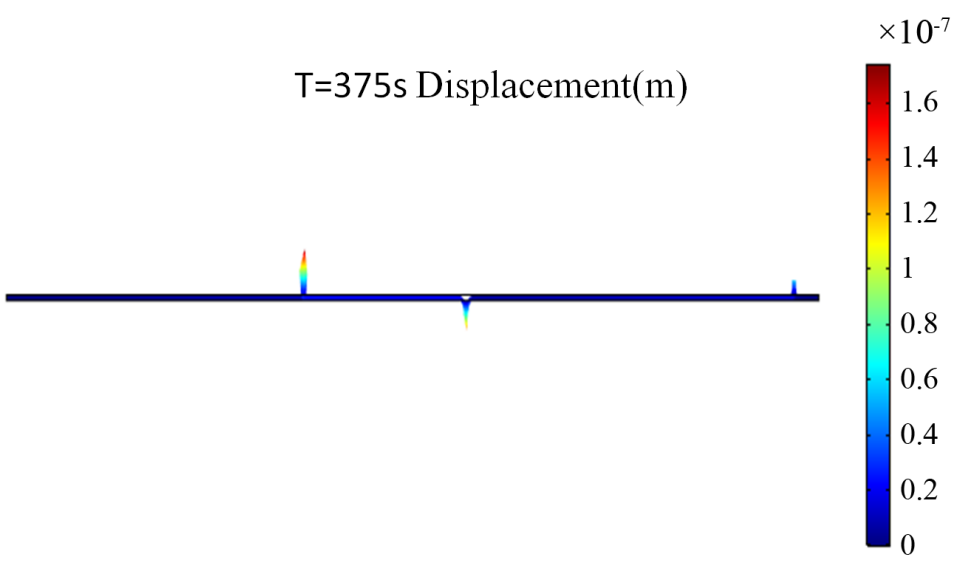

Figure 14. Displacement changes at the end of the sixth time compaction (Strong vibration).

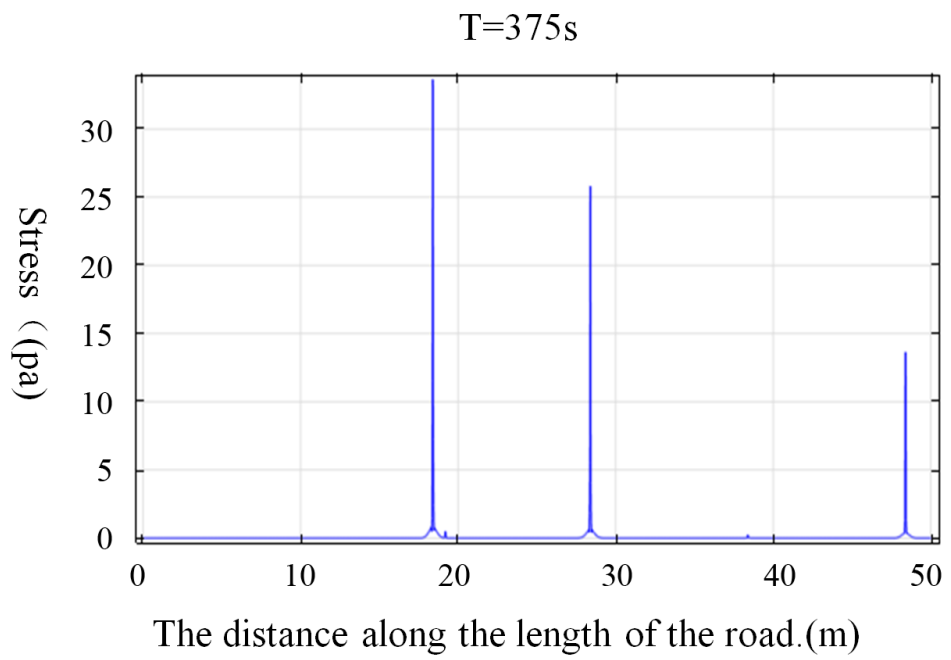

Figure 15. The stress changes at the end of the sixth compaction (Strong vibration).

third time strong vibration phase, compared to the road of the maximal displacement change is small, and the road surface the maximum stress of lower. The displacement is still small in the vibration end of the roller and the surrounding area. The maximum strength of pavement structure.

By more than six times the compaction, the results show that with the increase of compaction times, the displacement and stress of pavement present nonlinear immediately after the first increases, decreases, which embodies the road good compaction effect, which is consistent with the results of pavement compaction test. On this basis, analyzed the pavement compaction of displacement and stress under different position in the process of dynamic change process, and found that the road in the compaction process of displacement and stress appears asymmetric distribution form, this may be due to the road of internal moisture content and pore water seepage effects lead to the spread of the inter- 
nal stress and displacement of soil development of heterogeneous characteristics.

At the end of each compaction, the stress and displacement of the road have similar distribution pattern, and the maximum stress is located near the middle of the middle, and there is a large peak in many places.

\subsubsection{The Distribution Curve of Pavement Displacement under Different Compaction Time}

From Figures 16-21, it can be more intuitively reflected that the displacement along the length distribution of the road at the end of each time pressure is consistent with the result of cloud image. It can be seen from the figure that the displacement of the road surface is small, and the maximum displacement is all near the center near the middle, and the distribution of the multi-peak asymmetrical curve occurs. For example, when $t=62.5 \mathrm{~s}$ moment, roller is static pressure phase at the moment, at this point, the road in most regions of the displacement from the point of view of value are smaller, the maximal displacement of only 1.4 microns, and near the road along the length of a third and two-thirds. When to time $t=375 \mathrm{~s}$, the road in most regions of the displacement is relatively uniform, just near the road along the center of large displacement, the maximal displacement value of 0.16 microns, compared to before several stages, the road of the maximal displacement decrease significantly. Therefore, it can be proved that after experiencing the vibration compaction, the displacement of pavement structure gradually becomes smaller and the final area is flat, so the pavement structure becomes dense.

$\mathrm{T}=62.5 \mathrm{~s}$

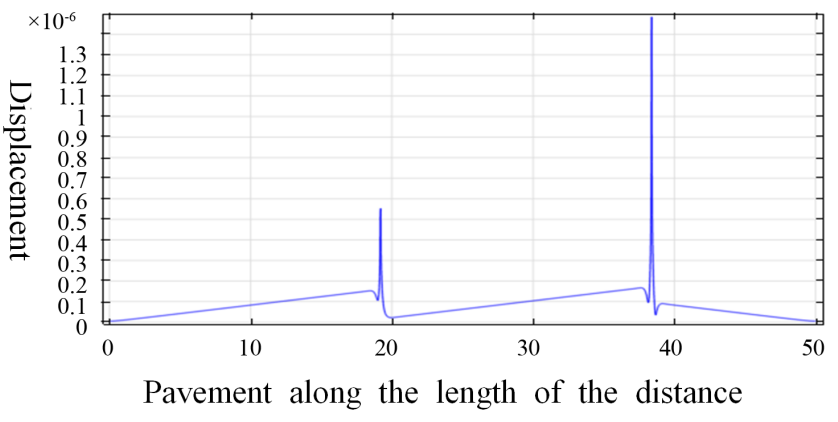

Figure 16. The first compaction is over (Static pressure).

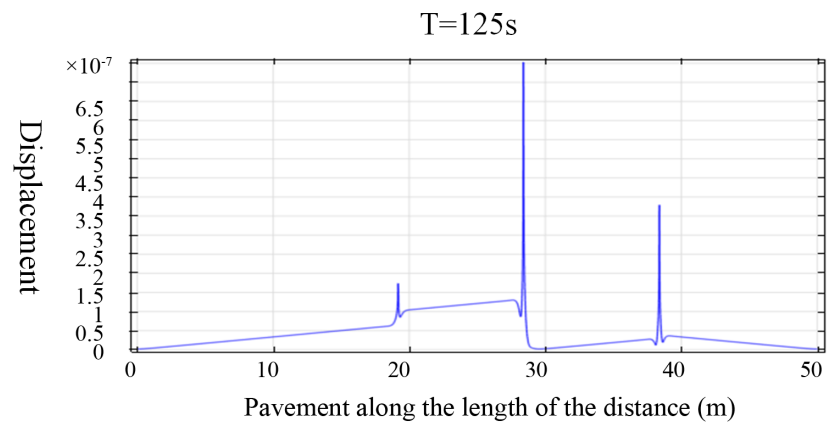

Figure 17. The second compaction is over (Weak vibration). 
$\mathrm{T}=187.5 \mathrm{~s}$

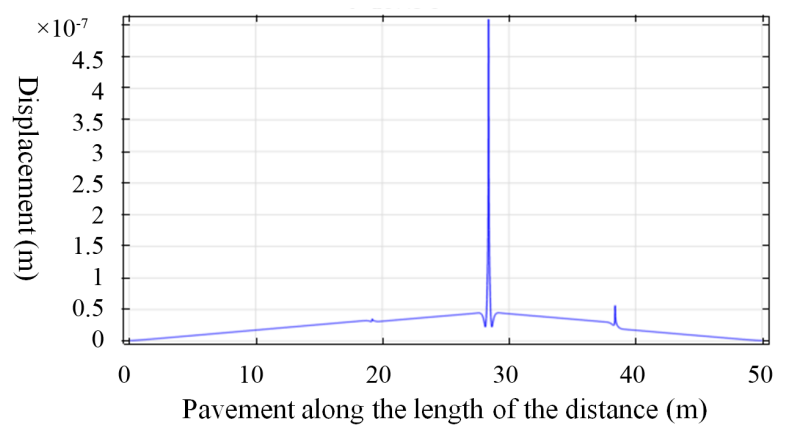

Figure 18. The third compaction is over (Strong vibration).

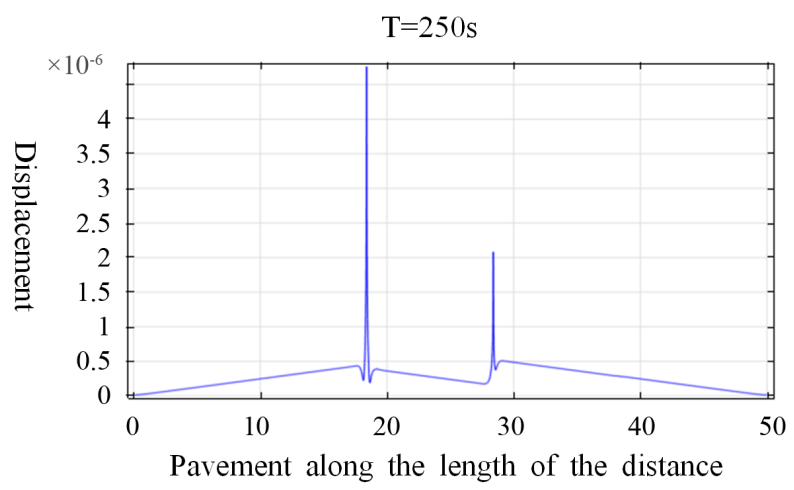

Figure 19. The fourth compaction is over (Strong vibration).

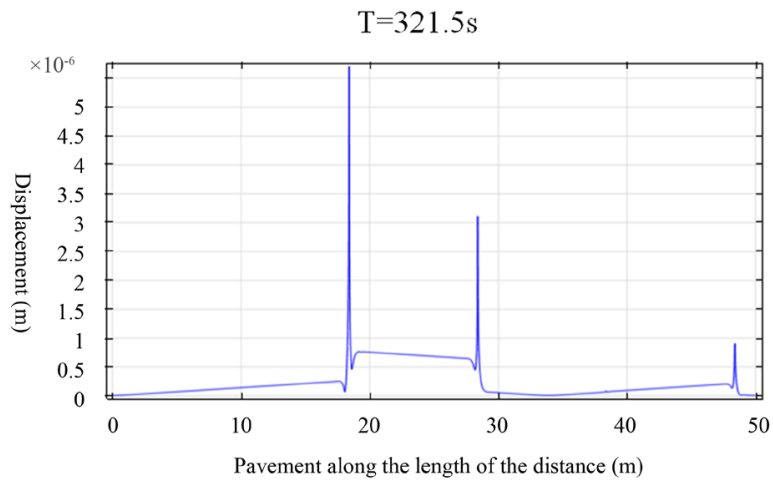

Figure 20. The fifth compaction is over (Strong vibration).

\section{Conclusions}

Based on analysis, this article through the establishment of two-dimensional finite element model of porous elastic medium road, the simulation calculation under the working condition of vibration compaction displacement and stress distribution of the pavement, road surface is analyzed under different compaction times mechanical properties, the results showed that:

1) With the increase of the number of compaction passes, the displacement and stress of the pavement exhibit a nonlinear change, which increases first and then decreases rapidly. When the number of rolling passes reaches six times, the 


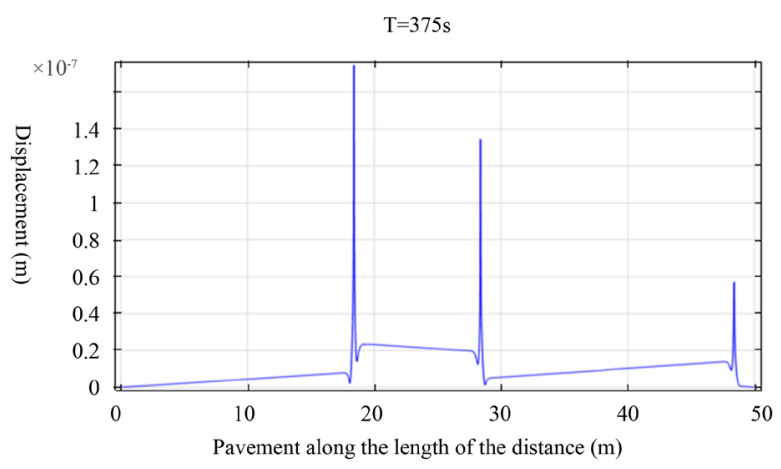

Figure 21. The sixth compaction is over (Strong vibration).

average displacement change rate between the fifth pass and the sixth pass is close to 0 . From the change of the overall average displacement curve, it can be seen that the average displacement of the first pass compaction is significantly lower than that of the sixth pass, and the actual test results also show that the soil has met the compaction degree. This shows that simulation of subgrade compaction test is relatively accurate.

2) Through simulation curve, the average displacement curve, and average stress from static pressure to the weak vibration and transition to strong vibration, the load is increased, and the weak to strong vibration change when there is a change of vibration, so in the third time in real time, displacement and stress will be recovered, because the outside of the load increase, but with the increase of compaction times, displacement and stress and decrease rapidly, reduce the size of the weaker than static pressure and vibration reducing effect is more apparent, this is also reflected the strong vibration effect than the weak vibration effect is good.

3) By analyzing the pavement compaction of displacement and stress under different positions in the process of dynamic change process, found the road surface displacement and stress in the compaction process appears asymmetric distribution form, this may be due to the road the influence of the internal moisture content and pore water infiltration due to leading to the spread of the internal stress of soil.

\section{References}

[1] Yang, Y. (2015) Briefing on the Important Points of Compaction Construction of Municipal Road Pavement. Journal of Goods and Quality.

[2] Zhang, Z.Q. (2017) Evaluation and Analysis of Subgrade Soft Compaction Based on CMV. Hebei University, Baoding.

[3] Anlian, S. (1996) Subgrade and Pavement Detection Technology. People's Transportation Press, Beijing.

[4] Xu, G.H., Luo, Z.H. and Tian, B. (2015) Summary of Development of Continuous Compaction Control Technology. Southwest Jiaotong University, Chengdu.

[5] Xu, G.H. (2005) Dynamic Monitoring Technology of Roadbed System Formation. Southwest Jiaotong University, Chengdu. 
[6] Du, X.-Y., Zhang, Q.-L., Kong, Y.-F. and Chen, C. (2016) Analysis of Frost Heave Mechanism of Coarse Soil in Subgrade of High-Speed Railway. Acta Crirtles Sinica, 12, 152-156.

[7] Kang, T. (2016) Energy-Saving Technology Analysis of Single Drum Vibratory Roller. Chang'an University, Xi'an.

[8] (June 2011) Intelligent Compaction Technology for HMA Applications. Generic-IC Specification for HMA.

[9] Huang, J.L. (2014) Research on Power Quality Analyzer Based on HHT.

[10] Wang, Y. (2014) Study of Vertical Stress Distribution in Soil under Vibration Wheel. Chang'an University, Xi'an. 